\title{
Glibenclamide-10-h Treatment Window in a Clinically Relevant Model of Stroke
}

\author{
J. Marc Simard • Seung Kyoon Woo • \\ Natalia Tsymbalyuk • Oksana Voloshyn • \\ Vladimir Yurovsky • Svetlana Ivanova • Ryan Lee • \\ Volodymyr Gerzanich
}

Received: 16 November 2011 /Revised: 23 February 2012 / Accepted: 28 February 2012 / Published online: 7 March 2012

(C) The Author(s) 2012. This article is published with open access at Springerlink.com

\begin{abstract}
Glibenclamide improves outcomes in rat models of stroke, with treatment as late as $6 \mathrm{~h}$ after onset of ischemia shown to be beneficial. Because the molecular target of glibenclamide, the sulfonylurea receptor 1 (Sur1)-regulated $\mathrm{NC}_{\text {Ca-ATP }}$ channel, is upregulated de novo by a complex transcriptional mechanism, and the principal pathophysiological target, brain swelling, requires hours to develop, we hypothesized that the treatment window would exceed $6 \mathrm{~h}$. We studied a clinically relevant rat model of stroke in which middle cerebral artery occlusion $(75 \%<$ reduction in LDF signal $\leq 90 \%$ ) was produced using an intra-arterial occluder. Recanalization was obtained $4.5 \mathrm{~h}$ later by removing the occluder. At that time, we administered recombinant tissue plasminogen activator (rtPA; $0.9 \mathrm{mg} / \mathrm{kg}$ IV over $30 \mathrm{~min}$ ). Immunolabeling showed modest expression of Sur1 $5 \mathrm{~h}$ after onset of ischemia, with expression increasing 7- to 11 -fold $(P<0.01)$ by $24 \mathrm{~h}$. Rats were administered either vehicle or glibenclamide $(10 \mu \mathrm{g} / \mathrm{kg}$ IP loading dose plus $200 \mathrm{ng} / \mathrm{h}$ by constant subcutaneous infusion) beginning 4.5 or $10 \mathrm{~h}$ after onset of ischemia. In rats treated at 4.5 or $10 \mathrm{~h}$,
\end{abstract}

J. M. Simard $(\bowtie) \cdot$ S. K. Woo $\cdot$ N. Tsymbalyuk $\cdot$ O. Voloshyn •

V. Yurovsky $\cdot \mathrm{S}$. Ivanova $\cdot$ R. Lee $\cdot$ V. Gerzanich

Department of Neurosurgery,

University of Maryland School of Medicine,

22 S. Greene Street, Suite S12D,

Baltimore, MD 21201-1595, USA

e-mail: msimard@smail.umaryland.edu

J. M. Simard

Department of Pathology,

University of Maryland School of Medicine,

Baltimore, MD 21201, USA

J. M. Simard

Department of Physiology,

University of Maryland School of Medicine,

Baltimore, MD 21201, USA glibenclamide significantly reduced hemispheric swelling at $24 \mathrm{~h}$ from (mean \pm SEM) $14.7 \pm 1.5 \%$ to $8.1 \pm 1.6 \%$ or $8.8 \pm$ $1.1 \%$ (both $P<0.01$ ), respectively, and significantly reduced 48-h mortality from $53 \%$ to $17 \%$ or $12 \%$ (both $P<0.01$ ), and improved Garcia scores at $48 \mathrm{~h}$ from $3.8 \pm 0.62$ to $7.6 \pm 0.70$ or $8.4 \pm 0.74$ (both $P<0.01$ ). We conclude that, in a clinically relevant model of stroke, the treatment window for glibenclamide extends to $10 \mathrm{~h}$ after onset of ischemia.

Keywords Cerebral ischemia $\cdot$ Stroke $\cdot$ Glibenclamide Sur1 · Sur1-regulated $\mathrm{NC}_{\mathrm{Ca}-\mathrm{ATP}}$ channel $\cdot$ Recombinant tissue plasminogen activator $\cdot$ Rat

\section{Introduction}

Glibenclamide confers protection in various rat models of stroke, including non-lethal models of thromboembolic, permanent and temporary (105 $\mathrm{min})$ occlusion, as well as models of malignant cerebral edema [21, 23, 25]. In these models, protection is manifested as significant improvements in edema, brain swelling, lesion size, white matter preservation, neurological function and mortality. Beneficial effects of glibenclamide have been reported independently using in vitro and in vivo models of ischemia/hypoxia [15, $18]$.

In cerebral ischemia, the molecular target of glibenclamide is the sulfonylurea receptor 1 (Sur1)-regulated $\mathrm{NC}_{\mathrm{Ca}}$ ATP channel. All members of the neurovascular unit upregulate the Sur1-regulated $\mathrm{NC}_{\mathrm{Ca}-\mathrm{ATP}}$ channel after ischemia. However, its role in endothelial cell swelling, which contributes to ischemia, and its role in dysfunction of interendothelial tight junctions, which contributes to edema formation and brain swelling, are particularly important for 
many of the beneficial effects observed from blocking the channel.

The Sur1-regulated $\mathrm{NC}_{\mathrm{Ca}-\mathrm{ATP}}$ channel is not constitutively expressed but is transcriptionally upregulated after onset of ischemia. Recent work showed that the molecular mechanism responsible for transcriptional upregulation of the channel in endothelium involves a two-step sequential gene activation process [30]. Hypoxia first activates hypoxia inducible factor 1 , which results in transcriptional upregulation of the transcription factor, specificity protein 1 (Sp1). Upregulation of $\mathrm{Sp} 1$, in turn, results in transcriptional upregulation of Sur1, which then goes on to form functional ion channels that are transported to and inserted into the cell membrane. This multistep mechanism involving sequential gene activation, channel assembly and transport predicts that a prolonged time would be required before the molecular target of glibenclamide is in place. Moreover, the principal pathophysiological target of glibenclamide, brain swelling, requires hours to develop [13, 20]. As a result, we hypothesized that the treatment window for glibenclamide would exceed $6 \mathrm{~h}$.

Here, we tested the hypothesis that glibenclamide would have a long treatment window in a clinically relevant rat model of stroke. Middle cerebral artery occlusion (MCAo) was produced using an intra-arterial occluder. Recanalization was obtained by removing the occluder at $4.5 \mathrm{~h}$, simulating intra-arterial mechanical clot retrieval [6]. At the same time, we administered rtPA at the latest time and at the dose used in humans $(0.9 \mathrm{mg} / \mathrm{kg} \mathrm{IV})[2,9]$. Briefly, we found that this model was associated with high mortality and severe neurological disability, and that glibenclamide administered at either 4.5 or $10 \mathrm{~h}$ after onset of ischemia significantly improved outcomes.

\section{Methods}

\section{Rat Model of Stroke}

All surgical procedures were approved by the Institutional Animal Care and Use Committee of the University of Maryland. Male Wistar rats (250-275 g; Harlan, Indianapolis, IN) were anesthetized (ketamine, $60 \mathrm{mg} / \mathrm{kg}$, and xylazine, $7.5 \mathrm{mg} / \mathrm{kg}, \mathrm{IP}$ ) and allowed to breath spontaneously room air supplemented with oxygen to maintain $90 \%<\mathrm{sO}_{2}<$ $99 \%$ by pulse oximetry. The procedures for intra-arterial MCAo via the cervical external carotid artery (ECA), for monitoring laser Doppler flowmetry (LDF) signals over the involved cortex, for monitoring blood gases, for implanting mini-osmotic pumps with catheters for delayed start of infusion, for post-operative recovery of the animals and for necropsy to establish stroke-related death, have been described $[23,25]$. Compared to our previous reports, the principal differences in the present study were that: (1) we used commercially available intra-arterial occluders (0.39 mm; catalogue \#4039PK5Re; Doccol Corp, Redlands CA); (2) the rats were re-anesthetized at $\sim 4 \mathrm{~h}$ to acquire IV access via the external jugular vein, to remove the occluder at $4.5 \mathrm{~h}$, to ligate the stump of the ECA, and to implant a mini-osmotic pump subcutaneously; (3) after removing the occluder, an infusion of rtPA [Cathflo Activase (Alteplase), Genetech, Inc., San Francisco, CA], 0.9 mg/kg IV over 30 min, was started; (4) at the time designated for treatment ( 4.5 or $10 \mathrm{~h}$ after onset of ischemia), rats received either vehicle or glibenclamide $(10 \mu \mathrm{g} / \mathrm{kg}$ IP loading dose plus start of constant subcutaneous infusion of $200 \mathrm{ng} / \mathrm{h}$ for $48 \mathrm{~h}$ ). The low dose of glibenclamide used here has been shown repeatedly not to cause hypoglycemia [21, 24, 25].

Blood gases immediately prior to MCAo were (mean \pm SD): $\mathrm{pO}_{2}, 147 \pm 18 \mathrm{mmHg} ; \mathrm{pCO}_{2}, 56 \pm 1 \mathrm{mmHg}$ and $\mathrm{pH}$, 7.29 \pm 0.01 ; glucose, $135 \pm 7$; Hct, $46 \pm 1 ; \mathrm{sO}_{2}, 97 \pm 1 ; \mathrm{pO}_{2}$, $149 \pm 23 \mathrm{mmHg} ; \mathrm{pCO}_{2}, 57 \pm 1 \mathrm{mmHg}$ and $\mathrm{pH}, 7.30 \pm 0.01$; glucose, $126 \pm 6$; Hct, $46 \pm 1 ; \mathrm{sO}_{2}, 96 \pm 1$; for vehicle vs. glibenclamide treated rats, respectively.

LDF signals were monitored during the $30 \mathrm{~min}$ following positioning of the MCA occluder. For the three groups (vehicle, 4.5- and 10-h glibenclamide), LDF signals were reduced by (mean \pm SEM): $84.5 \pm 0.7 \%, 81.6 \pm 2.1 \%$, and $83.7 \pm 1.2 \%$, respectively, which were not significantly different from each other (by analysis of variance [ANOVA], $P=0.3$ ).

\section{Drug Formulation and Pump Preparation}

A stock solution of glibenclamide was prepared by placing $25 \mathrm{mg}$ glibenclamide (\#G2539; meets USP testing; Sigma, St. Louis, MO) into $10 \mathrm{ml}$ dimethyl sulfoxide (DMSO). The solution to be loaded into the mini-osmotic pumps (Alzet 2001, $1.0 \mu \mathrm{l} / \mathrm{h}$; Alzet Corp., Cupertino, CA) was made by taking $2.3 \mathrm{ml}$ unbuffered normal saline (NS), adding $4 \mu \mathrm{l}$ of $10 \mathrm{~N} \mathrm{NaOH}$ (undiluted Fixanal; Riedel-deHaën, Seelze, Germany), then adding $200 \mu \mathrm{l}$ stock solution, in that order to prevent precipitation of drug. The solution to be used for the loading dose was made by adding $4 \mu \mathrm{l}$ of stock solution to $1 \mathrm{ml} \mathrm{NS}$. For vehicle controls, solutions were made with DMSO, NS and $\mathrm{NaOH}$, as above, but glibenclamide was omitted. The pumps were filled with a measured volume of solution $(222-238 \mu \mathrm{l})$, with the volume determined by the difference in mass before and after loading. After loading, the pumps were primed overnight in $\mathrm{NS}$ at $37^{\circ} \mathrm{C}$ with the outlet of the pump connected to a length of PE60 tubing that extended above the level of the priming solution, to prevent $\mathrm{H}^{+}$ions from entering the pump chamber. Prior to implanting, the outlet of the pump either was left unconnected, for immediate start of drug infusion, or it was connected to an empty catheter (PE60 tubing), $5.5 \mu \mathrm{l}$ in volume, to obtain a 5.5-h delay in the start of drug infusion [25]. 
During the course of these experiments, periodic checks were carried out to confirm proper loading and functioning of the pumps. At the end of an experiment (after strokerelated death or $48 \mathrm{~h}$ ), the pump was removed from the animal and function was assessed by assuring proper seating of the cap, and by measuring residual pump volume. Proper formulation and correct loading were assessed by measuring the glibenclamide concentration in the residual solution. The concentration of glibenclamide in the pump (nominally $200 \mu \mathrm{g} / \mathrm{ml}$ ) was measured spectrophotometrically (absorbance at $239 \mathrm{~nm}$ ) [8] and was compared to a standard solution prepared at the same time and stored in a glass vial. In one instance, these checks led to the exclusion of one rat when it was found that the pump had not been properly loaded.

\section{Stability of Glibenclamide Formulation In Vivo}

Experiments were carried out to assess the solubility of glibenclamide $(200 \mu \mathrm{g} / \mathrm{ml}$ in $8 \%$ DMSO/NS) at $\mathrm{pH} 6-8$. Solutions were prepared, centrifuged $(15,000 \times g$ for $10 \mathrm{~min}$ ) and the glibenclamide concentration of the solution was determined spectrophotometrically (absorbance at $239 \mathrm{~nm})$.

Experiments were carried out with five uninjured rats to determine the stability of glibenclamide solutions in vivo. Glibenclamide solutions $(2.5 \mathrm{ml}$ of $200 \mu \mathrm{g} / \mathrm{ml}$ in $8 \%$ DMSO/NS) were prepared using 1,2 or $4 \mu$ of $10 \mathrm{~N} \mathrm{NaOH}$ (undiluted Fixanal). These solutions were loaded into pumps. After priming (with the outlet protected as above), the pumps (one or two per rat) were implanted. At periodic intervals, pumps were removed from the animals and the concentration of glibenclamide in the pump solution was measured.

\section{Sample Size Calculation for the Model of Stroke}

Initial experiments with the model used here suggested that mortality rates of $\sim 50 \%$ and $\sim 20 \%$ likely would be encountered with vehicle vs. glibenclamide treatment. Power analysis was performed (Power and Precision; release 3.2) for a two-sample proportion with these rates. It was found that group sizes of $25-40$ would yield $61-82 \%$ power of rejecting the null hypothesis ( $\alpha=0.05$; two-tailed).

\section{Experimental Series and Study Groups}

In Series 1, 13 rats underwent MCAo plus rtPA administration as above; five rats were euthanized at $5 \mathrm{~h}$ after onset of ischemia (the end of the 30-min infusion of rtPA) and eight rats were euthanized $24 \mathrm{~h}$ after onset of ischemia; these brains were used for immunolabeling experiments. In Series 2, 46 rats underwent MCAo plus rtPA administration as above; 18 rats were administered vehicle and 18 rats were administered glibenclamide at $4.5 \mathrm{~h}$ after onset of ischemia (the time of recanalization); ten rats were administered glibenclamide at $10 \mathrm{~h}$ after onset of ischemia $(5.5 \mathrm{~h}$ after recanalization). Of the 36 rats treated at $4.5 \mathrm{~h}, 16$ (eight vehicle and eight glibenclamide) were euthanized at $10 \mathrm{~h}$, and the remainder were euthanized at $24 \mathrm{~h}$. Of the rats treated at $10 \mathrm{~h}$, all were euthanized at $24 \mathrm{~h}$. All of these brains were used to assess hemispheric swelling. In Series $3-5$, rats underwent MCAo plus rtPA administration as above; these rats were used to examine the effect of vehicle vs. glibenclamide administered at different times (4.5 or $10 \mathrm{~h}$ after onset of ischemia) on preclinical outcomes (mortality, Garcia scores, infarct size at $48 \mathrm{~h}$ ). In Series 3 (vehicle vs. 4.5 -h glibenclamide), Series 4 (vehicle vs. 10 $\mathrm{h}$ glibenclamide), and Series 5 (vehicle vs. 4.5 -h glibenclamide), there were 55,50 , and 40 rats, respectively. In each of these series, the allocation ratio was $\sim 1$ vehicle to 2 glibenclamide. All series were carried out by two surgeons performing the same experiment in tandem, which helped to control for surgeon variability. The 4.5-h experiment of Series 3 was repeated after several months as Series 5, which helped to control for temporal variability. No effect of administering vehicle at 4.5 vs. $10 \mathrm{~h}$ was uncovered, allowing data from all the vehicle-treated rats to be pooled.

\section{Exclusions}

Rats were not enrolled if LDF signals did not show sustained reduction of $75-90 \%$ for the 30 -min period of monitoring, or if the sustained reduction exceeded $90 \%$. The latter criterion was implemented due to the exceedingly high incidence of early death associated with $>90 \%$ reduction. Of the 145 rats in Series 3-5, 130 met the LDF inclusion criteria. Of the 130 eligible rats, 13 were excluded after treatment allocation as follows (numbers in parentheses denote the number of rats from the vehicle, 4.5-h, and 10$\mathrm{h}$ glibenclamide groups, respectively): subarachnoid hemorrhage $(1,2,0)$, subdural hemorrhage $(1,0,0)$, premature death before treatment $(2,2,0)$, no discernable infarct $(2,1,0)$, bilateral infarct $(0,1,0)$, technical problem with the treatment $(0,0,1)$. Final group sizes were: $51,41,25$ for vehicle, $4.5-\mathrm{h}$, and $10-\mathrm{h}$ glibenclamide treatment, respectively.

\section{Good Laboratory Practice}

Care was taken to follow good laboratory practice. Daily treatment allocation (vehicle vs. glibenclamide) was determined by one investigator (VG) using coin toss, except when the need arose to balance enrollment. Another investigator (SKW) prepared and coded the pumps and syringes and maintained the log of treatments for use later in decoding, but did not otherwise participate. Two surgeons (NT 
and OV), both blinded to treatment, independently performed surgeries, but did not participate in outcome evaluations. Preclinical outcomes (mortality, Garcia scores and necropsies) were determined by a separate investigator (VY) who was blinded to treatment. Measurements of TTC-lesion sizes and hemispheric swelling were performed by another investigator (SI) who was blinded to treatment.

\section{Immunohistochemistry}

Rats from Series 1 were used for immunohistochemistry. After transcardiac perfusion/fixation with $10 \%$ neutral buffered formalin and cryoprotection of the brain with $30 \%$ sucrose, cryosections were immunolabeled using goat antiSur1 antibody (1:200; SC-5789; Santa Cruz Biotechnology, Santa Cruz, CA) and, in some cases, co-labeled with laminin (1:200; FITC-conjugated; EY Laboratories, San Mateo CA) to identify microvessels. Alexa Fluor-555-conjugated, species appropriate secondary antibody (Invitrogen, Carlsbad, CA) was used for visualization. Omission of primary antibody was used as a negative control. The sections were coverslipped with polar mounting medium containing antifade reagent and the nuclear dye, 4',6' diamino-2phenylindole (DAPI) (Invitrogen) and were examined using epifluorescence microscopy. Previous studies from this laboratory confirmed the absence of labeling in control tissues, and the specificity of the antibody against Sur1 used here $[21,23,25]$.

\section{Quantitative Immunohistochemistry}

Unbiased measurements of signal intensity within regions of interest (ROI) were obtained using NIS-Elements AR software (Nikon Instruments, Melville, NY) from sections immunolabeled in a single batch, as previously described $[7,22]$. All ROI images for a given signal were captured using uniform parameters of magnification, area, exposure, and gain. Segmentation analysis was performed by computing a histogram of pixel intensity for a particular ROI. For SUR1, specific labeling was defined as pixels with signal intensity greater than $2 \times$ that of background, and the area occupied by pixels with specific labeling was used to determine the percent area with specific labeling (\% ROI). ROIs consisted of rectangular areas, $2.5 \times 6.0 \mathrm{~mm}$ that were positioned to encompass the watershed region of the anterior and middle cerebral arteries $\left(\mathrm{W}_{\mathrm{AM}}\right)$ and the watershed region of the posterior and middle cerebral arteries $\left(\mathrm{W}_{\mathrm{PM}}\right)$ (as delineated in Fig. 1a-d).

Hemispheric Swelling at 10 and $24 \mathrm{~h}$

Rats from Series 2 were used to assess swelling. For rats that died, the skull containing the brain was immersed in formalin for 3 days. Survivors were euthanized at 10 or $24 \mathrm{~h}$, perfused with NS then formalin, and the skull containing the brain was immersed in formalin for 3 days. Subsequently, 2-mm coronal sections of the fixed brains were prepared and imaged using a flatbed scanner. Images of six consecutive slices were analyzed using Photoshop (Adobe) to obtain area measurements of both hemispheres, which were used to compute hemispheric swelling in percent, a robust measure independent of the fixation procedure [17].

\section{Functional Outcome}

Neurological function was assessed using the modified Garcia score [19], with the only modification being that a score of 0 was assigned for death. Scores were determined at 24 and $48 \mathrm{~h}$ after onset of ischemia. Animals that survived were euthanized at $48 \mathrm{~h}$.

\section{Infarct Volume}

For both rats that succumbed to stroke-related death as well as those euthanized at $48 \mathrm{~h}$, brains were evaluated to obtain corrected infarct volumes. Coronal sections, $2 \mathrm{~mm}$ thick, were immersed in 2\% 2,3,5-triphenyltetrazolium chloride (TTC) (Sigma-Aldrich, USA) in NS for $20 \mathrm{~min}$ at $37^{\circ} \mathrm{C}$. The TTC-stained sections were imaged using a flatbed scanner. Images of five consecutive slices were analyzed using Photoshop (Adobe) to obtain area measurements of the TTC-negative region, and of the ipsilateral and contralateral TTC-positive regions, which were used to compute the "corrected" hemispheric infarct volume in percent, a robust measure independent of the processing procedure [17].

\section{Statistical Analysis}

Calculations were performed using either InStat, version 3.1 (GraphPad Software, Inc.) or OriginPro8 (OriginLab Corp.). Expression levels of Sur 1 at 5 vs. $24 \mathrm{~h}$ were analyzed using Student's $t$-test. Rates of mortality and of petechial hemorrhages were analyzed using a $2 \times 2$ contingency table with Fisher's exact test. Hemispheric swelling for the four groups of rats treated at $4.5 \mathrm{~h}$ was analyzed using a two-way ANOVA with the Bonferroni test. Hemispheric swelling for the single group treated with glibenclamide at $10 \mathrm{~h}$ was compared to swelling in groups treated at $4.5 \mathrm{~h}$ using Student's $t$-test. Garcia scores were compared between groups using the Kruskal-Wallis test with Dunn's post-hoc comparisons. The change in Garcia scores of individual rats between 24 and $48 \mathrm{~h}$ was analyzed using a Wilcoxon matchedpairs test. TTC-lesion volumes were analyzed using a oneway ANOVA with Bonferroni post-hoc comparisons. The 
Fig. 1 Sulfonylurea receptor 1 (Sur1) continues to be upregulated after recanalization. a-d Coronal sections of rat brains immunolabeled for Sur 1 $5 \mathrm{~h}(\mathbf{a}, \mathbf{c})$ or $24 \mathrm{~h}(\mathbf{b}, \mathbf{d})$ after onset of ischemia; note the immunolabeling for Sur1 in the watershed region of the anterior and middle cerebral arteries $\left(W_{A M}\right)(\mathbf{a}, \mathbf{b})$ and the watershed region of the posterior and middle cerebral arteries $\left(W_{P M}\right)$ (c, d) that increased with time. e, f Immunolabeling of $\mathrm{W}_{\mathrm{PM}}$ region $24 \mathrm{~h}$ after onset of ischemia shows prominent upregulation of Surl (red) in elongated structures that colabel for laminin (green), consistent with microvessels; nuclei labeled with DAPI (blue). $\mathbf{g}$ Quantitative immunohistochemistry showing large increases in Surl expression in $\mathrm{W}_{\mathrm{AM}}$ and $\mathrm{W}_{\mathrm{PM}}$ regions that developed between 5 and $24 \mathrm{~h}$ after onset of ischemia; five and eight rats, respectively; ${ }^{* *} P<$ 0.01 . For all experiments, MCAo was obtained using an intra-arterial occluder that was left in place for $4.5 \mathrm{~h}$, after which a 30 -min infusion of rtPA $(0.9 \mathrm{mg} / \mathrm{kg} \mathrm{IV})$ was started
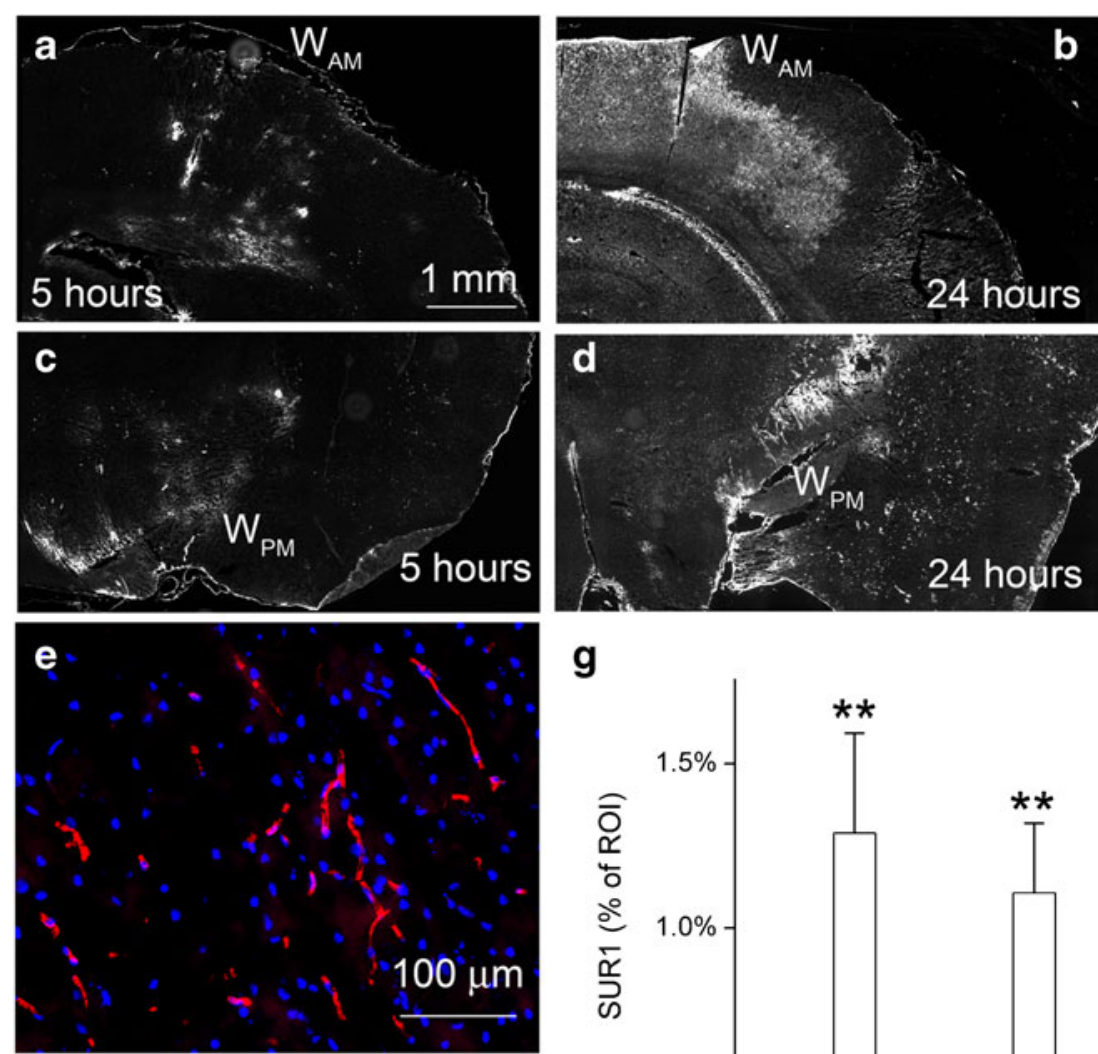

g

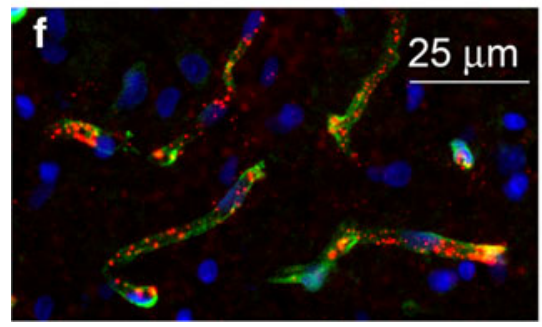

correlations between LDF signal and Garcia score, and between infarct volume and Garcia score were analyzed using the Spearman rank correlation.

\section{Results}

\section{Sur1 Upregulation}

Sur1 was previously shown to be upregulated in various rat models of stroke [21, 23, 25], but not in the model studied here with a prolonged time before reperfusion. The study of tissues harvested $5 \mathrm{~h}$ after onset of ischemia (after completing the IV infusion of rtPA) showed modest immunolabeling for Sur1 in the watershed region of the anterior and middle cerebral arteries $\left(\mathrm{W}_{\mathrm{AM}}\right)$ (Fig. 1a), as well as in the watershed region of the posterior and middle cerebral arteries $\left(\mathrm{W}_{\mathrm{PM}}\right)$ (Fig. 1c). Upregulation of Sur1 in watershed regions is typical [21]. Immunolabeling tissues harvested $24 \mathrm{~h}$ after onset of ischemia showed extensive necrosis in the MCA cortex (upregulation of Sur1 is not observed in necrotic tissues [21]), as well as prominent upregulation of Sur1 in both watershed regions (Fig. 1b, d). As previously reported [21], much of the upregulation in watershed regions localized to microvessels (Fig. 1e, f). Quantification showed that, in both watershed regions, Sur 1 expression at $24 \mathrm{~h}$ was 7 - to 11-fold greater than at $5 \mathrm{~h}$ (Fig. 1g), consistent with continued upregulation of Sur1 after recanalization.

\section{Formulation of Glibenclamide}

Glibenclamide (adopted US name, glyburide, $\mathrm{p} K_{\mathrm{a}}=5.3$ ) is a weak acid that is sparingly soluble in water, but whose solubility increase with $\mathrm{pH}$. We measured the solubility of glibenclamide spectrophotometrically (absorbance at $239 \mathrm{~nm}$; Fig. 2a) [8] at $\mathrm{pH}$ 6-8, when solutions were prepared at a concentration of $200 \mu \mathrm{g} /$ $\mathrm{ml}$ in NS containing $8 \%$ of the co-solvent, DMSO. Even with the co-solvent, $\mathrm{pH} 8$ was required to achieve $100 \%$ solubility (Fig. 2b). 
a
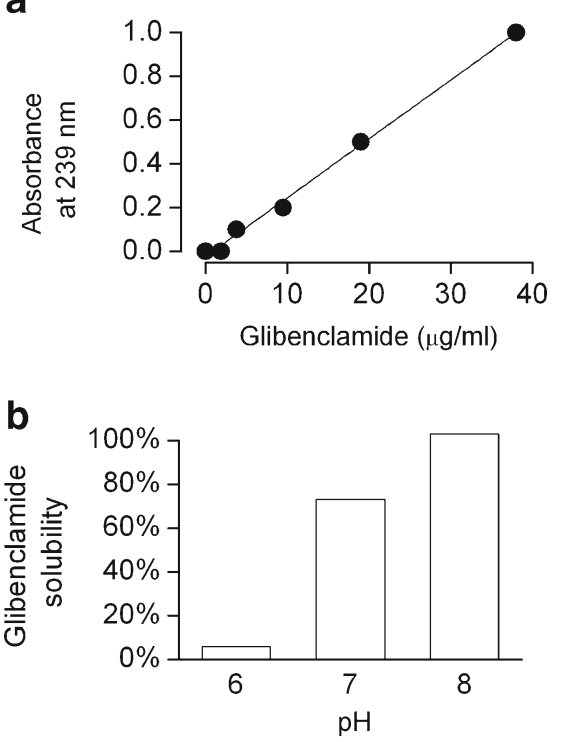

C

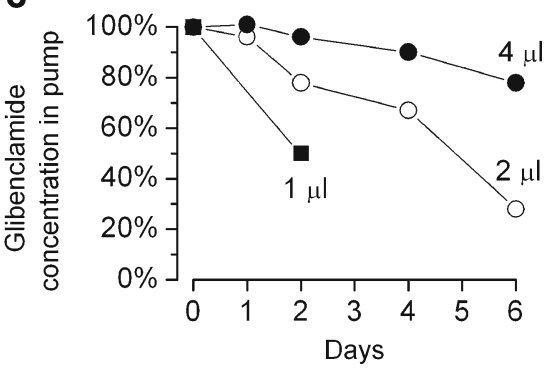

Fig. 2 Glibenclamide formulation. a Spectrophotometric measurement shows that absorbance at $239 \mathrm{~nm}$ is linearly related to the concentration of glibenclamide solubilized in normal saline supplemented with $8 \%$ dimethylsulfoxide $(D M S O)$; absorbance due to DMSO was subtracted. b The solubility of glibenclamide, prepared as a $200 \mu \mathrm{g} / \mathrm{ml}$ solution in NS supplemented with $8 \%$ DMSO, depends on $\mathrm{pH}$. $\mathbf{c}$ The stability over time of glibenclamide solutions $(2.5 \mathrm{ml}$ of $200 \mu \mathrm{g} / \mathrm{ml}$ in $8 \% \mathrm{DMSO} / \mathrm{NS}$ plus 1,2 , or $4 \mu \mathrm{l}$ of $10 \mathrm{~N} \mathrm{NaOH}$ ) placed inside of an implanted mini-osmotic pump depends on the amount of buffering capacity included in the formulation; buffering capacity supplied by the volume of $10 \mathrm{~N} \mathrm{NaOH}$ indicated; in $\mathbf{b}$ and $\mathbf{c}$, spectrophotometric measurements were made after a 10 -fold dilution

A drug solution at high $\mathrm{pH}$ loaded into a pump implanted into an animal is predicted to drift toward neutral $\mathrm{pH}$ as $\mathrm{H}^{+}$ ions from the body enter the drug solution, resulting in drug precipitating out of solution. The loss of high $\mathrm{pH}$ can be rapid, since $\mathrm{H}^{+}$ions are transported though water at a rate $\sim 5$ times faster than that of other cations whose diffusion is governed solely by thermal motion [3, 12]. Preventing the loss in high $\mathrm{pH}$ requires sufficient buffering capacity in the pump solution, in this case an excess of $\mathrm{OH}^{-}$ions, to maintain a stable drug concentration.

We examined the stability of solutions of glibenclamide inside of pumps implanted into uninjured rats. We found that a solution of glibenclamide $(2.5 \mathrm{ml}$ of $200 \mu \mathrm{g} / \mathrm{ml}$ in $8 \%$ DMSO/NS) prepared with 1 or $2 \mu \mathrm{l}$ of $10 \mathrm{~N} \mathrm{NaOH}(\mathrm{pH} 11.5$ or 12 , respectively) exhibited a progressive decline in concentration (Fig. 2c, filled squares, empty circles). By contrast, a solution prepared with $4 \mu \mathrm{l}$ of $10 \mathrm{~N} \mathrm{NaOH}$ (pH 12.3) was stable for 2 days and lost $\sim 20 \%$ over 6 days (Fig. 2c, filled circles). The latter formulation was used for the preclinical experiments described below.

Swelling

Edema and hemispheric swelling were previously shown to be reduced by glibenclamide [21, 23, 25], but not in the model studied here or when administered as late as $10 \mathrm{~h}$ after onset of ischemia. First, we measured hemispheric swelling 10 and $24 \mathrm{~h}$ after onset of ischemia in rats administered either vehicle or glibenclamide at $4.5 \mathrm{~h}$ (Fig. 3a-c). Glibenclamide given at $4.5 \mathrm{~h}$ reduced swelling measured at $10 \mathrm{~h}$ from $7.8 \pm 1.2 \%$ to $4.1 \pm 1.4 \%$. Glibenclamide given at $4.5 \mathrm{~h}$ reduced swelling measured at $24 \mathrm{~h}$ from $14.7 \pm 1.5 \%$ to $8.1 \pm 1.3 \%$. Statistical analysis showed that the effects of both time (progression of swelling between 10 and $24 \mathrm{~h}$ ) and treatment (vehicle vs. glibenclamide) were significant (both $P<0.001$, by two-way ANOVA).

We also measured hemispheric swelling at $24 \mathrm{~h}$ in rats administered glibenclamide at $10 \mathrm{~h}$ (Fig. 3c). We used the previous data-vehicle-treated rats assessed at $10 \mathrm{~h}$ that exhibited $7.8 \pm 1.2 \%$ hemispheric swelling-as controls for this experiment. When glibenclamide was administered at $10 \mathrm{~h}$, swelling at $24 \mathrm{~h}$ was only slightly more $(8.8 \pm 1.1 \%$; $P=0.56$, by $t$-test) than at $10 \mathrm{~h}$ without treatment, suggesting that glibenclamide largely arrested the formation of edema during this period of time. When glibenclamide was administered at $10 \mathrm{~h}$, swelling at $24 \mathrm{~h}$ was significantly different compared to vehicle-treated rats $(P=0.005$, by $t$-test $)$.

\section{Mortality}

Mortality was previously shown to be reduced by glibenclamide [21,23], but not in the model studied here or with a treatment delay of $10 \mathrm{~h}$. Mortality was assessed $48 \mathrm{~h}$ after onset of ischemia. For the three groups (vehicle, $4.5 \mathrm{~h}$, and $10 \mathrm{~h}$ glibenclamide), mortality was $53 \%, 17 \%$, and $12 \%$, respectively (Fig. 3d). Values with glibenclamide administered at both 4.5 and $10 \mathrm{~h}$ were significantly different from that in the control group (both $P<0.01$ ). Values with glibenclamide at 4.5 and $10 \mathrm{~h}$ were not statistically different from each other $(P=0.7)$.

\section{Garcia Scores}

Garcia scores were assessed $24 \mathrm{~h}$ after onset of ischemia. For the three groups (vehicle, $4.5 \mathrm{~h}$, and $10 \mathrm{~h}$ glibenclamide), scores were (mean \pm SEM) $3.8 \pm 0.55,6.6 \pm 0.51$, and $8.0 \pm 0.52$, respectively (Fig. 3e, empty bars). Values with 
Fig. 3 Glibenclamide

improves outcomes in a

clinically relevant model of stroke. Hemispheric swelling imaged at $24 \mathrm{~h}$ in rats administered vehicle (a) or glibenclamide (b) $4.5 \mathrm{~h}$ after onset of ischemia; vertical bars denote the location of midline structures; the scatter plot (c) shows the percent hemispheric swelling at 10 and $24 \mathrm{~h}$ in rats administered vehicle (empty circles) or glibenclamide at $4.5 \mathrm{~h}$ (Glib $4.5 \mathrm{~h}$; filled gray circles) or $10 \mathrm{~h}$ (Glib $10 \mathrm{~h}$; filled black circles) after onset of ischemia; 8-10 rats per group; $* * * P<0.001$, pertains to analysis of the four groups treated at $4.5 \mathrm{~h}$. d Mortality, assessed at $48 \mathrm{~h}$, in rats administered vehicle, glibenclamide at $4.5 \mathrm{~h}$ after onset of ischemia (4.5 h Glib) or glibenclamide at $10 \mathrm{~h}$ after onset of ischemia (10 h Glib); 51,41 , and 25 rats in the three groups, respectively; ${ }^{* *} P<$ 0.01 ; data at 4.5 and $10 \mathrm{~h}$ are not statistically different from each other $(P=0.7)$. e Garcia scores, assessed at $24 \mathrm{~h}$ (empty bars) and $48 \mathrm{~h}$ (gray bars), in rats administered vehicle, glibenclamide at $4.5 \mathrm{~h}$ after onset of ischemia (4.5 h Glib), or glibenclamide at $10 \mathrm{~h}$ after onset of ischemia (10 h Glib); same rats as in $\mathbf{d} ; * * P<0.01$; $* * * P<0.001$; data at 4.5 and $10 \mathrm{~h}$ are not statistically different from each other $(P>$ $0.05)$. f Representative infarct visualized using TTC (left), and comparison of infarct volumes measured at $48 \mathrm{~h}$ in rats administered vehicle or glibenclamide at 4.5 or $10 \mathrm{~h}$ after onset of ischemia, as indicated $(P=0.5)$
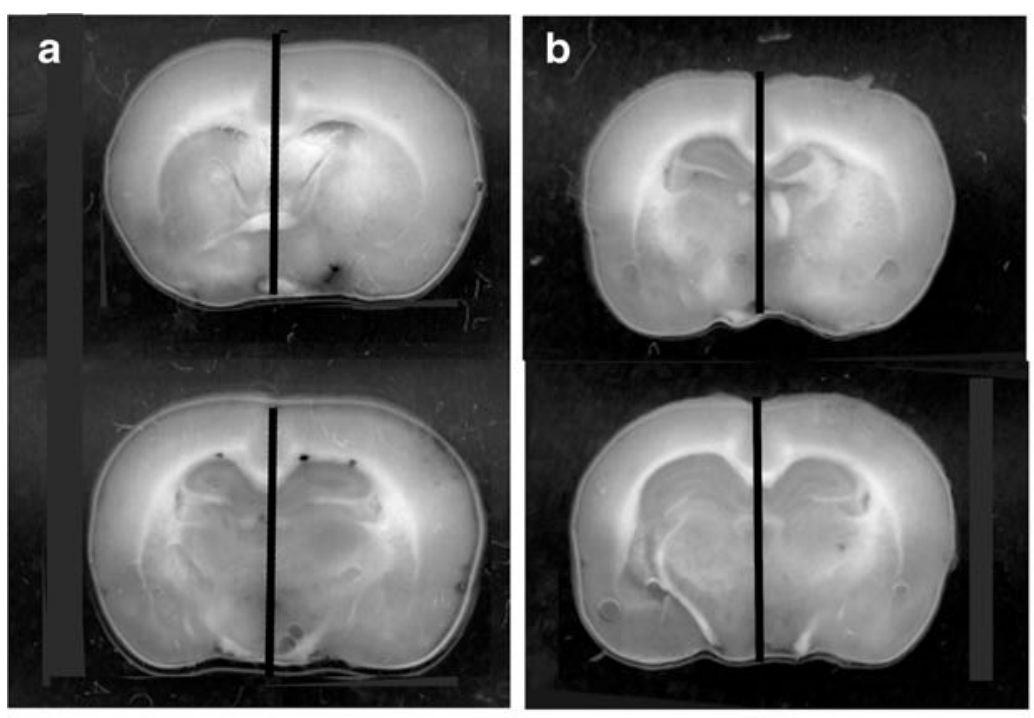

c

d
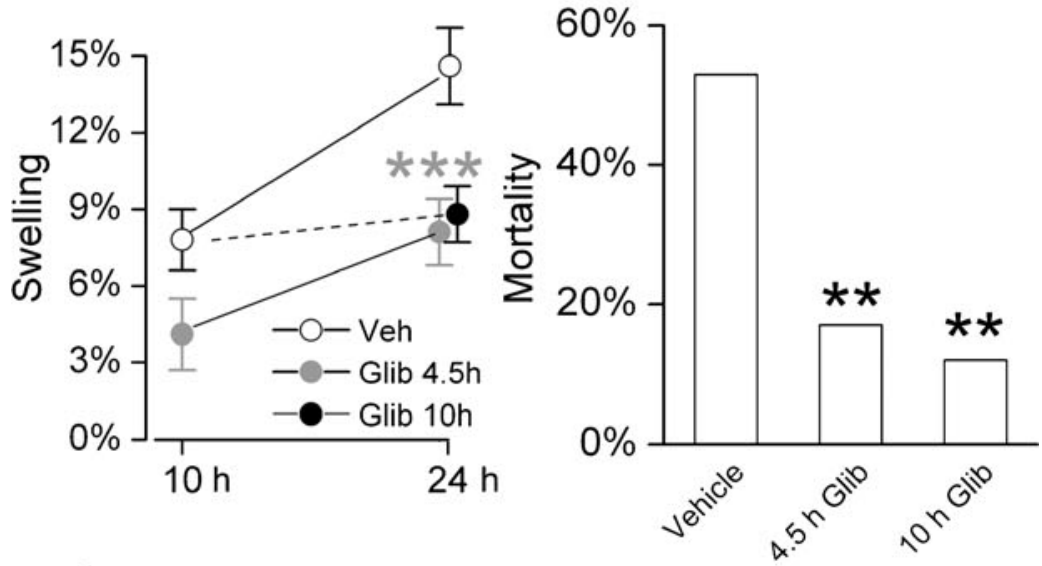

e
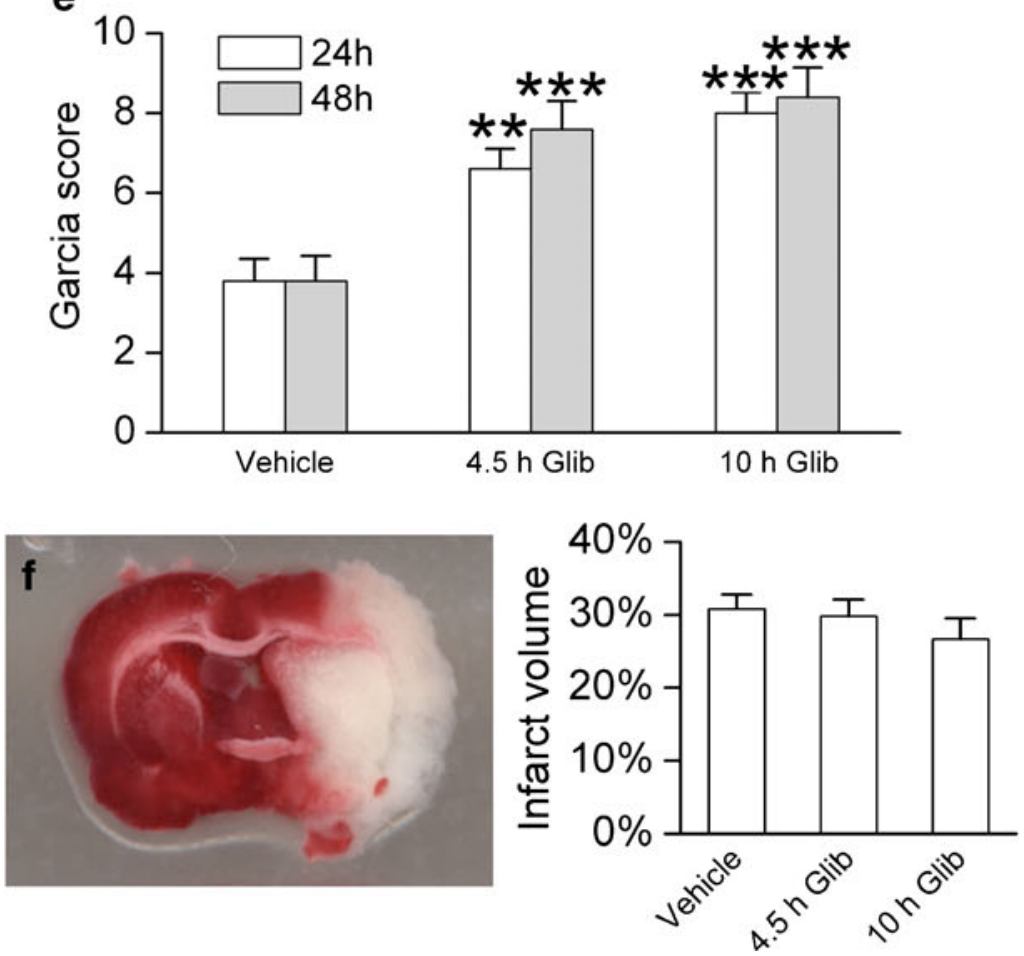
glibenclamide administered at $4.5(P<0.01)$ and $10 \mathrm{~h}(P<$ 0.001 ) were significantly different from that in the control group. Values with glibenclamide at 4.5 and $10 \mathrm{~h}$ were not statistically different from each other $(P>0.05)$.

Garcia scores were assessed $48 \mathrm{~h}$ after onset of ischemia. For the three groups (vehicle, $4.5 \mathrm{~h}$, and $10 \mathrm{~h}$ glibenclamide), scores were (mean \pm SEM) $3.8 \pm 0.62,7.6 \pm 0.70$, and $8.4 \pm 0.74$, respectively (Fig. 3e, gray bars). Values with glibenclamide administered at 4.5 and $10 \mathrm{~h}$ were significantly different from that in the control group (both $P<0.001$ ). Values with glibenclamide at 4.5 and $10 \mathrm{~h}$ were not statistically different from each other $(P>0.05)$.

In vehicle-treated rats that survived $48 \mathrm{~h}$ with a Garcia score $>1$, the Garcia score at $48 \mathrm{~h}$ was negatively correlated with the reduction in LDF signal recorded at the onset of ischemia (Spearman $r=-0.62 ; P<0.01$ ). By contrast, in rats treated with glibenclamide at $4.5 \mathrm{~h}$, this correlation was lost (Spearman $r=0.28 ; P=0.1$ ). The significant negative correlation in the vehicle-treated group may have been due to continued brain swelling, which would be expected to be worse with a more severe ischemic insult. The loss of correlation with glibenclamide would be consistent with reduced swelling in this group (Fig. 3a-c) [21, 23].

For rats that survived the first $24 \mathrm{~h}$ (Garcia score $>0$ ), we also examined the changes in Garcia scores that occurred subsequently. In vehicle-treated rats, 4/28 survivors (14\%) died between 24 and $48 \mathrm{~h}$, and overall Garcia scores were unchanged $(6.9 \pm 0.5$ and $6.9 \pm 0.7$ at 24 and $48 \mathrm{~h}$, respectively; $P=0.61$ ). In rats treated with glibenclamide at 4.5 or $10 \mathrm{~h}, 3 / 59$ survivors (5\%) died between 24 and $48 \mathrm{~h}$, and overall scores improved between 24 and $48 \mathrm{~h}$, from $8.0 \pm 0.2$ to $8.9 \pm 0.4(P<0.01)$.

\section{Infarct Size}

TTC-infarct volumes were assessed $48 \mathrm{~h}$ after onset of ischemia (Fig. 3f). For the three groups (vehicle, $4.5 \mathrm{~h}$, and $10 \mathrm{~h}$ glibenclamide), corrected infarct volumes were (mean \pm SEM): $30.8 \pm 2.0 \%, 29.8 \pm 2.3 \%$, and $26.7 \pm 2.8 \%$, respectively $(P=0.5)$.

In vehicle-treated rats that survived $48 \mathrm{~h}$ with a Garcia score $>1$, the Garcia score at $48 \mathrm{~h}$ was negatively correlated with infarct volume (Spearman $r=-0.81 ; P<0.0001$ ). By contrast, in rats treated with glibenclamide at $4.5 \mathrm{~h}$, this correlation was lost (Spearman $r=-0.34 ; P=0.06$ ).

\section{Hemorrhagic Transformation}

Confluent areas of hemorrhagic transformation of an ischemic region, as often reported with $10 \mathrm{mg} / \mathrm{kg} \mathrm{rtPA}$ in rats [14], were not seen with the dose of $0.9 \mathrm{mg} / \mathrm{kg}$ used here, but in some rats, discrete petechial hemorrhages, $0.4-1 \mathrm{~mm}$, were observed. For the three groups (vehicle, $4.5 \mathrm{~h}$, and $10 \mathrm{~h}$ glibenclamide), petechial hemorrhages were identified in 6/ $51,6 / 41$, and $3 / 25$ rats, respectively $(P=0.76,0.99$, respectively, compared to control). In all cases, a single petechial hemorrhage was located in the caudate; in two of the rats, a second petechial hemorrhage also was located in the cortex.

\section{Validation of Drug Delivery System}

To confirm proper functioning of the pumps in the preclinical studies reported above, frequent periodic checks were made of the volume of solution remaining in the pump at the time of either stroke-related death or planned euthanasia (48 h). In 50 cases tested, the residual volume was appropriate for the time of removal of the pump from the animal, given the measured volume that was loaded $(222-238 \mu \mathrm{l})$, the time when priming was started, and the nominal rate of delivery of $1 \mu \mathrm{l} / \mathrm{h}$. The same samples also were tested to confirm the presence of vehicle (20 pumps) vs. drug ( 30 pumps), as well as the concentration of glibenclamide in solution. Measurements of glibenclamide solutions removed at $\sim 24$ and $48 \mathrm{~h}$ showed values of $94 \pm 1.3 \%$ and $86 \pm 1.8 \%$ of the expected concentration, respectively (16 and 14 pumps each), which accorded well with the previous measurements in Fig. 1c.

\section{Discussion}

There are two important new findings in the present study. First, our data indicate that glibenclamide is highly effective when administered as late as $10 \mathrm{~h}$ after onset of ischemia. Previous work showed efficacy of glibenclamide out to $6 \mathrm{~h}$ [23]. However, recent elucidation of the molecular mechanism responsible for transcriptional upregulation of the Sur1-channel [30], combined with the fact that brain swelling after ischemia takes hours to develop [13,20], suggested that the treatment window for glibenclamide might exceed $6 \mathrm{~h}$. This was confirmed here, with data indicating undiminished efficacy out to $10 \mathrm{~h}$. Previous work with rat models of MCAo showed treatment efficacy (infarct volume or neurological function) for a variety of agents when treatment was initiated at $10 \mathrm{~h}$ after onset of ischemia (ischemic insult: 2$\mathrm{h}$ MCAo [28, 29]), at $12 \mathrm{~h}$ (ischemic insult: 1-h [32], 1.5$\mathrm{h}$ [10], and 2-h [27] MCAo), and at $18 \mathrm{~h}$ (ischemic insult: 20-min MCAo [10]). To our knowledge, no agent other than glibenclamide has shown treatment efficacy on mortality from malignant edema and on neurological function when administered at $10 \mathrm{~h}$ in a model with 4.5-h MCAo.

Secondly, in the model used here, glibenclamide appeared to dissociate functional outcomes (mortality and Garcia scores) from infarct volumes. Although previous reports that examined either permanent occlusion $[18,25]$ or a shorter ischemic time (105 $\mathrm{min})$ [25] indicated that glibenclamide 
reduces lesion volumes, here lesion volumes were not changed by treatment. The 4.5 -h duration of ischemia used here apparently was associated with a maximum ischemic insult when measured at $48 \mathrm{~h}$, leaving little opportunity for a reduction in infarct volume by drug. Many reports indicate that $3 \mathrm{~h}$ of mechanical occlusion produce maximum infarct volumes when measured $48 \mathrm{~h}$ later, and that longer occlusion times do not increase infarct size further [4, 31]. Similarly, in rat models, administration of $\mathrm{rtPA}(10 \mathrm{mg} / \mathrm{kg})$ is ineffective in reducing infarct volume when given more than $2-4 \mathrm{~h}$ after onset of ischemia $[4,16,33]$. Together, these studies indicate that it should not be surprising that infarct volumes would have been similar in vehicle vs. glibenclamide groups. However, despite the same infarct volumes, functional outcomes were significantly better with glibenclamide, indicating that some factor other than infarct volume determined functional outcome. The other factor likely was edema or brain swelling. Prior studies showed that edema and brain swelling are significantly ameliorated by glibenclamide [18, 21, 23, 25], as was reaffirmed in the present study in a different model of stroke.

An important goal of preclinical stroke studies is the development and use of clinically relevant models that may be helpful in predicting the outcome of clinical trials. Numerous models of ischemic stroke in rats have been described, but few precisely mimic clinical stroke [5]. Truly permanent occlusion, as studied in rats with occluders permanently positioned at the ICA bifurcation, rarely occurs in humans because of eventual spontaneous recanalization. Also, nearly all transient ischemia models studied in rats utilize relatively short ischemia times in order to preclude fatal swelling. In the model we studied, recanalization was obtained by removing the occluder at $4.5 \mathrm{~h}$, simulating intraarterial mechanical clot retrieval [6]. At the same time, we administered rtPA at the latest time and at the dose used in humans $(0.9 \mathrm{mg} / \mathrm{kg}$ IV) [2, 9]. Although this dose is expected to be minimally thrombolytic in rats [11], it was important to avoid the excess toxicity associated with $10 \mathrm{mg} / \mathrm{kg}$ rtPA [9] in order to maintain relevance to humans. In addition, use of a sub-thrombolytic dose served to mimic the situation frequently encountered in humans wherein administration of rtPA does not lead to timely recanalization or reperfusion $[1,26]$. Finally, our outcomes were focused on improvements in mortality, brain swelling and neurological function, rather than a reduction in lesion volume, because of the indisputable clinical impact of the first three-rtPA, currently the only drug approved for use in stroke, was approved based on its demonstrated ability to improve functional outcomes, not because it reduces lesion volumes. These considerations led to the model described here, which we believe to be highly relevant clinically.

An important limitation of the present study is that we did not examine the effect of occluder removal plus rtPA administration at $4.5 \mathrm{~h}$ on LDF signals or other measures of cerebral blood flow. As a result, we do not know the status or timing of cerebral reperfusion in this model. In our previous study [23], removing the occluder at $6 \mathrm{~h}$ (no rtPA administered) often resulted in delay of reperfusion (judged by LDF signals) by up to $2 \mathrm{~h}$, consistent with development of thrombosis during occlusion, and delayed spontaneous thrombolysis after occluder removal. It is likely that in the model studied here, thrombolysis was eventually achieved, but when this occurred, in which vessels it occurred, and whether it occurred too late to salvage tissues, is not known. Another limitation of the present study is that we did not study survivors beyond $48 \mathrm{~h}$. However, our data indicate that rats administered glibenclamide, but not vehicle, improved significantly between 24 and $48 \mathrm{~h}$. Also, our previous experience with the Garcia scoring system showed that rats exhibiting scores of 6 or better at $48 \mathrm{~h}$ rarely die and almost always improve functionally [23]. Thus, it seems unlikely that the beneficial effects of glibenclamide observed here at $48 \mathrm{~h}$ would have been negated by longer observation.

In summary, we describe a rat model of stroke that was designed to mimic several aspects of the human condition, including severe ischemia $(75 \%<$ reduction in LDF signals $\leq 90 \%$ ), abrupt recanalization at $4.5 \mathrm{~h}$, administration at $4.5 \mathrm{~h}$ of the dose of rtPA used in humans, and evaluation of clinically relevant endpoints. The insult produced, combined with other features of the model, yielded a severe injury with high mortality and poor functional outcome. Using this model, we demonstrated that outcomes (swelling, mortality, and neurological function) were significantly improved when low-dose glibenclamide was administered at either 4.5 or $10 \mathrm{~h}$ after onset of ischemia.

Acknowledgements This work was supported by grants to JMS from the National Heart, Lung, and Blood Institute (HL082517) and the National Institute of Neurological Disorders and Stroke (NS061808).

Conflict of interest JMS holds a US patent (\# 7,285,574), "A novel non-selective cation channel in neural cells and methods for treating brain swelling," and is a member of the scientific advisory board and holds shares in Remedy Pharmaceuticals. No support, direct or indirect, was provided to JMS, or for this project, by Remedy Pharmaceuticals.

Open Access This article is distributed under the terms of the Creative Commons Attribution License which permits any use, distribution, and reproduction in any medium, provided the original author(s) and the source are credited.

\section{References}

1. del Zoppo GJ, Poeck K, Pessin MS, et al. Recombinant tissue plasminogen activator in acute thrombotic and embolic stroke. Ann Neurol. 1992;32:78-86. 
2. del Zoppo GJ, Saver JL, Jauch EC, et al. Expansion of the time window for treatment of acute ischemic stroke with intravenous tissue plasminogen activator: a science advisory from the American Heart Association/American Stroke Association. Stroke. 2009;40:2945-8.

3. Erdey-Gruz T. Transport phenomena in electrolyte solutions. London: Adam Higler; 1974.

4. Fagan SC, Nagaraja TN, Fenstermacher JD, et al. Hemorrhagic transformation is related to the duration of occlusion and treatment with tissue plasminogen activator in a nonembolic stroke model. Neurol Res. 2003;25:377-82.

5. Fisher M, Feuerstein G, Howells DW, et al. Update of the stroke therapy academic industry roundtable preclinical recommendations. Stroke. 2009;40:2244-50.

6. Furlan AJ. Clot retrieval for stroke should be restricted to clinical trials: no. Stroke. 2010;41:194-5.

7. Gerzanich V, Ivanov A, Ivanova S, et al. Alternative splicing of cGMP-dependent protein kinase I in angiotensin-hypertension: novel mechanism for nitrate tolerance in vascular smooth muscle. Circ Res. 2003;93:805-12.

8. Gianotto EA, Arantes RP, Lara-Filho MJ, et al. Dissolution test for glibenclamide tablets. Quim Nova. 2007;30:1218-21.

9. Haelewyn B, Risso JJ, Abraini JH. Human recombinant tissueplasminogen activator (alteplase): why not use the 'human' dose for stroke studies in rats? J Cereb Blood Flow Metab. 2010;30:900-3.

10. Khan M, Elango C, Ansari MA, et al. Caffeic acid phenethyl ester reduces neurovascular inflammation and protects rat brain following transient focal cerebral ischemia. J Neurochem. 2007;102:365-77.

11. Korninger C, Collen D. Studies on the specific fibrinolytic effect of human extrinsic (tissue-type) plasminogen activator in human blood and in various animal species in vitro. Thromb Haemost. 1981;46:561-5.

12. Kornyshev AA, Kuznetsov AM, Spohr E, et al. Kinetics of proton transport in water. J Phys Chem B. 2003;107:3351-66.

13. Kotwica Z, Hardemark HG, Persson L. Intracranial pressure changes following middle cerebral artery occlusion in rats. Res Exp Med (Berl). 1991;191:99-104.

14. Murata Y, Rosell A, Scannevin RH, et al. Extension of the thrombolytic time window with minocycline in experimental stroke. Stroke. 2008;39:3372-7.

15. Nistico R, Piccirilli S, Sebastianelli L, et al. The blockade of $\mathrm{K}(+)-$ ATP channels has neuroprotective effects in an in vitro model of brain ischemia. Int Rev Neurobiol. 2007;82:383-95.

16. Okubo S, Igarashi H, Yamaguchi H, et al. Therapeutic time window of rt-PA on embolic stroke in rat. Int Congr Series. 2003;1252:203-7.

17. Overgaard K, Meden P. Influence of different fixation procedures on the quantification of infarction and oedema in a rat model of stroke. Neuropathol Appl Neurobiol. 2000;26:243-50.

18. Sayeed I, Wali B, Ishrat F, et al. Glybenclamide administration attenuates infarct volume, hemispheric swelling and functional deficits following permanent focal cerebral ischemia in rats.
Society of Neuroscience Meeting, Washington DC. 2011;Poster \# $62.05 / \mathrm{FF} 11$

19. Shimamura N, Matchett G, Tsubokawa T, et al. Comparison of silicon-coated nylon suture to plain nylon suture in the rat middle cerebral artery occlusion model. J Neurosci Meth. 2006;156:161-5.

20. Silasi G, MacLellan CL, Colbourne F. Use of telemetry blood pressure transmitters to measure intracranial pressure (ICP) in freely moving rats. Curr Neurovasc Res. 2009;6:62-9.

21. Simard JM, Chen M, Tarasov KV, et al. Newly expressed SUR1regulated $\mathrm{NC}(\mathrm{Ca}-\mathrm{ATP})$ channel mediates cerebral edema after ischemic stroke. Nat Med. 2006;12:433-40.

22. Simard JM, Geng Z, Woo SK, et al. Glibenclamide reduces inflammation, vasogenic edema, and caspase-3 activation after subarachnoid hemorrhage. J Cereb Blood Flow Metab. 2009;29:317-30.

23. Simard JM, Tsymbalyuk N, Tsymbalyuk O, et al. Glibenclamide is superior to decompressive craniectomy in a rat model of malignant stroke. Stroke. 2010;41:531-7.

24. Simard JM, Tsymbalyuk O, Ivanov A, et al. Endothelial sulfonylurea receptor 1-regulated NC Ca-ATP channels mediate progressive hemorrhagic necrosis following spinal cord injury. J Clin Invest. 2007;117:2105-13.

25. Simard JM, Yurovsky V, Tsymbalyuk N, et al. Protective effect of delayed treatment with low-dose glibenclamide in three models of ischemic stroke. Stroke. 2009;40:604-9.

26. von Kummer R, Holle R, Rosin L, et al. Does arterial recanalization improve outcome in carotid territory stroke? Stroke. 1995;26:581-7.

27. Wang C, Liu JL, Sang HF, et al. Therapeutic time window of flurbiprofen axetil's neuroprotective effect in a rat model of transient focal cerebral ischemia. Chin Med J (Engl). 2008;121:2572-7.

28. Williams AJ, Berti R, Dave JR, et al. Delayed treatment of ische$\mathrm{mia} /$ reperfusion brain injury: extended therapeutic window with the proteosome inhibitor MLN519. Stroke. 2004;35:1186-91.

29. Williams AJ, Myers TM, Cohn SI, et al. Recovery from ischemic brain injury in the rat following a $10 \mathrm{~h}$ delayed injection with MLN519. Pharmacol Biochem Behav. 2005;81:182-9.

30. Woo SK, Kwon MS, Geng Z, et al. Sequential activation of hypoxia-inducible factor 1 and specificity protein 1 is required for hypoxia-induced transcriptional stimulation of Abcc8. J Cerebr Blood Flow Metabol. 2011.

31. Yanamoto H, Nagata I, Niitsu Y, et al. Evaluation of MCAO stroke models in normotensive rats: standardized neocortical infarction by the 3VO technique. Exp Neurol. 2003;182:261-74.

32. Yu YM, Kim JB, Lee KW, et al. Inhibition of the cerebral ischemic injury by ethyl pyruvate with a wide therapeutic window. Stroke. 2005;36:2238-43.

33. Zhang L, Zhang ZG, Zhang R, et al. Adjuvant treatment with a glycoprotein IIb/IIIa receptor inhibitor increases the therapeutic window for low-dose tissue plasminogen activator administration in a rat model of embolic stroke. Circulation. 2003;107:2837-43. 